\title{
Preliminary Study of Skull Polymorphims of Tupaia glis in Peninsular Malaysia by using MorphoJ
}

\author{
Azrinaaini Md Yusoffa*, Jayaraj Vijaya Kumaranb,c, Nurul Farah Diyana Mohd Tahird, Seri Intan Mokhtara \\ a Faculty of Agro Based Industry, Universiti Malaysia Kelantan, Malaysia \\ ${ }^{b}$ Faculty of Earth Science, Universiti Malaysia Kelantan, Malaysia \\ 'Faculty of Biological Science, Universiti Sains Malaysia, Malaysia \\ ${ }^{d}$ Faculty of Resource Science and Technology, Universiti Malaysia Sarawak, Malaysia \\ *Corresponding author: azrinayusoff@gmail.com
}

\section{Article history}

Received : 15 August 2014

Received in revised form :

15 October 2014

Accepted :15 November 2014

Graphical abstract

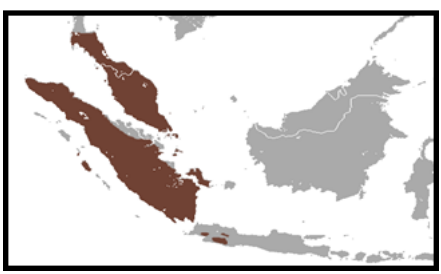

\section{Abstract}

A global geographic fragmentation has caused the diversity of animals and plants worldwide, mostly to the population of small mammals. In Malaysia, there are a lot of natural barriers that can separate the population of small mammals including common treeshrew, Tupaia glis. In this study, the polymorphism of ninety (90) Tupaia glis in Peninsular Malaysia is carried out by comparing the skulls of the species from different states by using MorphoJ analysis. This is carried out to know the landmark of the species and the shape changes.

Keywords: Small mammals; polymorphism; skulls; shape changes; MorphoJ

(C) 2015 Penerbit UTM Press. All rights reserved.

\subsection{INTRODUCTION}

Small mammals are mammals that have a maximum weight of less than $5 \mathrm{~kg}$ and are mainly consist of mammals from the order Rodentia, Chiroptera, Lagomorpha, Erinacepmorpha, Soricomorpha, and Scandentia [1,2]. They are the most diverse group of mammals but yet little information is known about them as compared to larger enigmatic mammals such as tigers and elephants. Fifteen percent of mammals are categorized as data deficient in the IUCN Red List of Threatened Species, with bats and rodents dominating the list of data deficient species [3]. Thus there is a big gap of knowledge on the distribution, abundance and conservation status of small mammals. This is confounded by the fact that small mammals are hard to be identified and need to be captured for such purposes, making surveys very costly due to transport of trap and field equipments.

Tupaia (derived from a Malay word 'tupai', meaning 'squirrel'. T. glis can be differentiated from the small tree squirrels in many details of anatomy and behaviour. They have very long muzzle with a total of 38 teeth, with pointed incisors and several premolars. All feet of common tree shrew have five well-developed digits with claws [4]. According to [4] Francis (2005), T.glis have hair that are banded dark and pale on the upper parts and buff on the under parts. It appears finely speckled with a strong reddish tint and usually has a pale stripe on each shoulder.

According to [5] Boonsong, 1977 there are 8 recognized subspecies found in mainland Thai which are: $T$. g. ferruginea, $T$. g. wilkensoni, T. g. clarissa, T. g. belangeri, T. g. chinensis, T. g. laotum, T. g. olivacea and T. g. concolor. This all subspecies has their own colour variations that differentiate them from each other, the pelage colour is widely variable for subspecies. [6] Hill (1960) has demonstrated a cline of colour for the mainland tree shrews, with the ones in the South brighter and more reddish then the ones in the North. The colour variation seems to be related to changes in rainfall and temperature, with the brighter, redder colours correlated with high humidity and temperature and grey or grey-brown colours correlated with lower temperature and humidity. 